\title{
Modulating Effects of Emotional Valence on Recognition Memory for High-Arousal Pictures $^{*}$
}

\section{Efectos moduladores de la valencia emocional sobre la memoria de reconocimiento para imágenes de alto arousal}

a Autor de correspondencia. Correo electrónico: jose.fernandez.rey@usc.es

Para citar este artículo: Fernández-Rey, J., \& Redondo, J. (2017). Modulating effects of emotional valence on recognition memory for high-arousal pictures, Universitas Psychologica, 16(1), 1-10. http://dx.doi.org /10.11144/Javeriana.upsy16-1.meev

\begin{abstract}
The main aim of this paper was to provide new evidence on the effects of valence on recognition memory of emotional pictures, on the basis of rigorous experimental control of stimulus material. Valence was manipulated using pleasant and unpleasant pictures, keeping arousal constant at a high level. A reference condition with a neutral value in both dimensions was also included. We found greater discrimination and a more conservative response bias, as well as slower recognition decisions, for pleasant pictures. Also worthy of mention is the high positive correlation between response times and discrimination measures just for such pictures. These results would be consistent with an adaptive interpretation based on motivation and personal relevance of emotional information.
\end{abstract}

Keywords

emotional pictures; valence; arousal; recognition memory; response times.

\section{RESUMEN}

El principal objetivo del presente trabajo fue aportar nueva evidencia sobre los efectos de la valencia en el reconocimiento de imágenes de contenido emocional, a partir de un riguroso control experimental del material estimular. Se manipuló la valencia a niveles agradable y desagradable, manteniendo constante el arousal a un nivel alto. Se incluyó también una condición de referencia con un valor neutro en ambas dimensiones. Se encontró una mejor discriminación, un sesgo de respuesta más conservador y un reconocimiento más lento para las imágenes agradables. Además, solo para estas imágenes existió alta correlación positiva entre tiempos de respuesta y discriminación. Estos resultados serían consistentes con una interpretación de carácter adaptativo basada en la motivación y relevancia personal de la información emocional.

Palabras clave

imágenes de contenido emocional; valencia; arousal; memoria de reconocimiento; tiempos de respuesta. 
There is already a substantial body of evidence on the effects of improving long-term memory produced by emotion. The free recall of different types of stimuli (including words, phrases, pictures) tends to be greater if they contain positive or negative emotional content than if they are emotionally neutral (for reviews, see Bradley, 1994; Reisberg \& Heuer, 2004). Similarly, studies on autobiographical memory show that it is easier to recall personal events with emotional relevance than without it (e.g., Conway, 1995; Schulkind \& Woldorf, 2005).

There is also evidence of a higher probability of recognition memory for positive or negative stimuli in comparison with emotionally neutral ones. Nonetheless, the experimental results are less consistent than in the case of recall, particularly when short retention periods are employed. Thus, for example, equivalent performance has been obtained for the recognition of negative and neutral words (Windmann \& Kutas, 2001) or for pictures with emotional and neutral content (Johansson, Mecklinger, \& Treese, 2004). Moreover, in certain studies no significant differences have been found between the discrimination of pleasant and unpleasant pictures (e.g. Bradley, Greenwald, Petry, \& Lang, 1992), while in others greater discrimination for unpleasant (e.g. Gordillo et al., 2010; Ochsner, 2000) or pleasant pictures (e.g. Atienza \& Cantero, 2008; Fernández-Rey \& Redondo, 2007) has been reported.

On the other hand, when studying the effects of emotion on recognition memory, the question of how the bias in the decision affects memory performance is also of great interest. Emotion may render the decision criterion more liberal, by increasing the probability of judging an item as "old", irrespective of whether the item has been previously studied or not (emotion-induced recognition bias). Accordingly, a more liberal bias has been found for words with unpleasant content in comparison with neutral ones (e.g. Windmann \& Kutas, 2001) or for pictures with unpleasant content in comparison with pleasant content (e.g. Fernández-Rey \& Redondo, 2007;
Ochsner, 2000). Nonetheless, in other studies a more conservative response bias has been obtained for pictures with unpleasant content (e.g. Gordillo et al., 2010).

In order to better understand this inconsistency in results, we must take into account certain important problems which studies aimed at evaluating the effects of emotional valence on recognition memory need to tackle.

One of the problems may be due to failing to take into account that emotional and neutral stimuli are probably different from each other in more than one dimension (Kensinger, 2004). Hence the importance of considering emotional stimuli on the basis of their coordinates in a two-dimensional "valence-arousal" space, which allows the differential contribution to the performance of both dimensions to be dissociated from memory (Bradley, 1994; Kensinger, 2004). The lack of control for the arousal dimension, confusing the effects thereof with those of valence, is one of the possible reasons for the inconsistency of results in emotional stimulus recognition (Kensinger, 2004). Although certain studies (e.g. Bradley et al., 1992, Experiment 1; Conroy \& Polich, 2007; Redondo \& FernándezRey, 2010) have controlled the effect of arousal by maintaining the level thereof constant, using the "International Affective Picture System" (IAPS; Lang, Bradley, \& Cuthbert, 1999), this procedure has not been habitual in the literature in this field. Nonetheless, if our aim is to reach precise conclusions on the nature and magnitude of the effects of valence on recognition memory, arousal must be strictly controlled in order to be able to suitably isolate the aforesaid effects.

Another common problem is the possible ceiling effect in memory performance, since the accuracy in recognising emotional material is usually high (especially in the case of pictures), including with long retention intervals. Hence in a number of studies (e.g. Bradley et al., 1992; Redondo \& Fernández-Rey, 2010) no significant differences have been detected in accuracy on the basis of the emotional content of the pictures used, attaining values close to the ceiling effect, 
for both pleasant and unpleasant pictures. In order to obviate the aforementioned effect, certain factors which increase discrimination difficulty can be controlled, including the use of brief exposure periods to the stimuli (Gordillo et al., 2010; Ochsner, 2000) or stimuli with similar content in both phases, as conducted in this study. Moreover, within quantitative measures, latency measurements or response times must be used in addition to accuracy. These measures may also be useful for weighting the contribution in recognition decisions of the "recollection" and "familiarity" processes, which have been proposed through dual process models (for a review thereof, see Yonelinas, 2002). "Recollection" is a relatively slow process which requires additional attentional resources, whilst "familiarity" is a rapid, automatic process, through which one could assume that rapid responses reflect "familiarity" and slow ones imply a greater contribution from "recollection" (see Yonelinas, 2002).

In order to study the effect of valence on the recognition of emotional pictures, in this study the arousal dimension will be strictly controlled, maintaining its level constant, in this case with a high value and the valence dimension will be manipulated to levels of pleasant and unpleasant content. A reference condition with a neutral value in valence and arousal will also be included. This will contribute to the rigorous experimental control of the stimulus material employed. To the best of our knowledge, this is the first study on recognition memory to contemplate the use of pictures which are arousing for both categories of valence (positive and negative) in contrast with neutral pictures in both dimensions (valence and arousal). We shall also use response time measures, assuming that these can reflect "familiarity/recollection". The retention interval will also be manipulated to levels of immediate recognition and delayed response recognition (15 minutes). The foregoing will provide convergent measures for detecting the modulating effects of emotional valence on recognition memory for high-arousal pictures.

\section{Method}

Participants, materials and instruments

Participants consisted of 120 (38 males and 82 females) Psychology undergraduate students aged 19-23.

The stimuli employed were emotional pictures from the IAPS, system, selected on the basis of the standard valence and arousal values obtained among the Spanish population (Moltó et al., 1999). In order to evaluate the IAPS pictures, the Self-Assessment Manikin (SAM; Lang 1980) was used; more specifically, a computer version adapted on the basis of the original SAM original (see Fernández-Rey \& Redondo, 2007). With this instrument each picture can be evaluated in the valence and arousal dimensions using a nine-point scale; values range from " 1 " (low valence/arousal) to "9" (high valence/arousal). In the valence dimension, the SAM ranged from "unpleasant" (represented by a frowning figure) to "pleasant" (represented by a figure with a happy expression). In the arousal dimension, the SAM ranges from "calm" (represented by a sleepy figure) to "excited" (represented by a figure with eyes wide open).

A PC was used to both present the IAPS pictures and to record the subject's responses. The picture sequences were programmed and automated in all phases of the experiment using Superlab Pro (version 2.0) software.

\section{Procedure}

The initial phase of the experiment consisted of familiarising the subjects with regard to the evaluation of IAPS pictures with SAM. In the second phase, 30 pictures were shown randomly ("old pictures"; 10 pleasant, 10 unpleasant, and 10 neutral). After the presentation of each picture, the participant had to evaluate it in the valence and arousal dimensions using SAM. In the third phase, the 30 pictures used in the previous phase were presented ("old pictures") along with 60 pictures which they were seeing for the first time ("new pictures"). Hence, the 
$\mathrm{old} /$ new picture ratio was $1: 2$. The total of 90 pictures was presented in random sequence, with the constraint that no more than two original pictures could appear consecutively. Participants used the " 1 " key on the numerical keypad if they believed that the picture had been presented in the previous phase ("YES responses") and the "2" key if they believe that they had not seen it in the previous phase ("NO responses"), with the order of keys being reversed for half of the participants. Participants were asked to press the keys as rapidly as possible while attempting to avoid making errors. With the aim of evaluating the effect of the delay on recognition, half of the participants started the third phase immediately after the previous one (non-delay group). The other half did so 15 minutes after the end of the second phase (delay group). During this time, the subjects in the delay group had to read a text on memory related with the objectives of the experiment.

In order to homogenise the distribution of the new and original pictures in the affective space, the selection thereof was made taking into account the normative valence and arousal values. Thus, for pleasant and unpleasant pictures, high arousal was selected and a high and low valence, respectively. For neutral pictures, values close to the neutral point in each dimension were selected (i.e., close to " 5 " on the SAM scale).

For greater control in picture selection ${ }^{[1]}$, it was verified that the valence of the old pleasant pictures $(M=7.18 ; S D=0.57)$, was significantly higher than that of the old unpleasant pictures $(M=2.93 ; S D=0.62), t(9)=60.52, p<0.001$, and that, for the new pictures, the valence of the pleasant pictures $(M=7.26 ; S D=0.42)$ was greater than for the unpleasant pictures $(M=2.68 ; S D=0.54), t(19)=73.84, p<0.001$. It was also verified for the old pictures that arousal for the pleasant pictures $(\mathrm{M}=6.55 ; \mathrm{SD}$ $=0.44)$ was statistically similar to that of the unpleasant ones $(M=6.45 ; S D=0.30), t(9)=$ $-0.50, p>0.05$. Likewise, for the new pictures, the arousal for the pleasant pictures $(M=6.41$; $S D=0.50$ ) was similar to that for the unpleasant ones $(M=6.59 ; S D=0.42), t(19)=-1.17, p>$
0.05 . Additionally, it was verified that the valence of the old neutral pictures $(M=5.01 ; S D=0.53)$ was significantly lower than that of the pleasant ones, $t(9)=-35.48, p<0.001$, and greater than that of the unpleasant ones, $t(9)=21.56, p<$ 0.001 . In the same manner, the valence of the new neutral pictures $(M=5.03 ; S D=0.59)$ was significantly lower than that of the new pleasant ones, $t(19)=46.53, p<0.001$, and greater than that of the new unpleasant ones, $t(19)=$ $49.71, p<0.001$. Finally, the arousal for the old neutral pictures $(M=4.86$; $S D=0.76)$ was significantly lower than for old pleasant pictures, $t(9)=-5.11, p=0.001$, and for old unpleasant pictures, $t(9)=-6.31, p<0.001$. Similarly, the new neutral pictures $(M=5.03 ; S D=0.90)$ also had a significantly lower arousal value than the pleasant pictures, $t(19)=-6.22, p<0.001$, and the unpleasant pictures, $t(19)=-6.36, p<0.001$.

Pleasant pictures included pictures with erotic content and related with adventure sports. Unpleasant pictures showed aversive content related fundamentally with unpleasant faces or animals, disasters, threatening weapons, and war pictures. Neutral pictures included stimuli such as objects from everyday life (buildings, household utensils) and non-threatening people or animals. As indicated above, with the aim of rendering recognition more difficult and thus avoid the ceiling effect, efforts were made to use stimuli of the same semantic category in both the initial and recognition phases. Thus, if an erotic picture of a couple was selected as the "old picture", pictures of this type (and in the same proportion) were used as "new pictures" in the recognition phase. This type of control has also been used in other papers (see Ochsner, 2000) studying the effects of the IAPS on the recognition memory.

\section{Results}

With the aim of studying the modulating effects of the emotional valence of pictures on recognition memory, in addition to discrimination and bias measurements, the response times were also analysed. In addition, 
an analysis of bivariate correlations between the aforementioned variables was performed. Greenhouse-Geisser corrections were used in the ANOVAs whenever there was more than one degree of freedom, and significant differences within the main factors were assessed using Bonferroni corrections. Effect sizes were computed for relevant ANOVA effects and are reported as partial eta squared $\left(\eta^{2}\right)$. A significance level of $p<0.05$ was adopted for all analyses.

\section{Discrimination and bias}

Recognition memory performance was examined by analysing discrimination and bias measures derived from signal detection theory $\left(A^{\prime}\right.$ and $B{ }_{D}$, respectively; Donaldson, 1992; Snodgrass, Levy-Berger, \& Haydon, 1985). A' is a nonparametric analogue of $\mathrm{d}^{\prime}$ and its values range between 0 and 1 , with 0.5 reflecting random performance. Snodgrass et al. (1985) proposed a procedure for calculating this parameter. The appropriate bias measurement for $A^{\prime}$ is $B^{\prime \prime}{ }_{D}$. Donaldson (1992) developed a procedure to obtain this parameter, which takes values between -1 and +1 (negative values indicate a liberal bias, positive ones a conservative bias, and 0 no bias ${ }^{[2]}$ ). Table 1 shows the values of $A^{\prime}$ and $B{ }_{D}$, for groups with and without delay.

\section{TABLE 1}

Measurements of memory performance, response times (mean and standard deviations), and Pearson correlations between measures of memory performance, as a function of Valence, and Group

\begin{tabular}{ccccccccc}
\hline & \multicolumn{4}{c}{$\begin{array}{c}\text { Discrimination } \\
\text { and Bias }\end{array}$} & \multicolumn{2}{c}{ Response Times } & \multicolumn{3}{c}{ Correlation Analyses } \\
\hline Group & Valence & $A^{\prime}$ & $B^{\prime \prime}{ }_{D}$ & Old & New & RT- $A^{\prime}$ & RT- $B^{\prime \prime}{ }_{D}$ & $A^{\prime}-B^{\prime \prime}{ }_{D}$ \\
& & & & & & & & \\
\hline \multirow{4}{*}{ No delay } & Pleasant & 0.61 & 0.79 & 1055 & 983 & $0.54^{* *}$ & -0.05 & -0.21 \\
& & $(0.06)$ & $(0.24)$ & $(166)$ & $(166)$ & & & \\
& Unpleasant & 0.41 & 0.52 & 1004 & 984 & 0.15 & -0.12 & -0.19 \\
& & $(0.04)$ & $(0.20)$ & $(162)$ & $(159)$ & & & \\
& Neutral & 0.48 & 0.38 & 967 & 981 & -0.16 & 0.07 & $-0.62^{* *}$ \\
& & $(0.06)$ & $(0.21)$ & $(174)$ & $(153)$ & & & \\
& Pleasant & 0.62 & 0.78 & 1071 & 1032 & $0.41^{* *}$ & 0.02 & $-0.31^{*}$ \\
& & $(0.06)$ & $(0.25)$ & $(139)$ & $(155)$ & & & \\
Delay & Unpleasant & 0.40 & 0.51 & 1051 & 1010 & -0.14 & -0.08 & $-0.41^{* *}$ \\
& & $(0.06)$ & $(0.23)$ & $(176)$ & $(149)$ & & & \\
& Neutral & 0.51 & 0.39 & 1017 & 1008 & 0.10 & 0.03 & $-0.52^{* *}$ \\
& & $(0.08)$ & $(0.21)$ & $(145)$ & $(157)$ & & & \\
\hline
\end{tabular}

Note: Standard deviations are given in the parenthesis. ${ }^{*} p<0,05 ; * *_{p}<0.01$ Source: own work.

\section{Discrimination results}

For the non-delay group, a statistically significant effect for Valence was obtained, $F(1,59)=$ 112.54, MSE $=0.49, \eta^{2}=0.66, p<0.001$. Subsequent comparisons of the mean values between each pair of conditions (see Table 1) revealed that the mean value of $A^{\prime}$ for pleasant pictures was significantly higher than for unpleasant and neutral ones; similarly, the value of $A^{\prime}$ for negative pictures was significantly lower than for neutral ones (Bonferroni correction, $p<0.001)$. In the delay group, a statistically significant effect for Valence was also obtained, $F(159)=101.17, \mathrm{MSE}=0.39, \eta^{2}=0.63, p<$ 0.001 . The results of the subsequent comparisons followed the same pattern as for the nondelay group. Thus, the mean value of $A^{\prime}$ for pleasant pictures was significantly higher than for unpleasant and neutral ones, and the value of $A^{\prime}$ for negative pictures was significantly lower than for neutral ones (Bonferroni correction, $p<$ 0.001).

\section{Bias results}

For the non-delay group, a statistically significant effect for valence was obtained, $F(159)=501.12$, MSE $=4.19, \eta 2=0.89, \mathrm{p}<0.001$. The value of $B_{D}{ }_{D}$ for pleasant pictures was significantly higher than for unpleasant and neutral ones; the value of $\mathrm{B}_{\mathrm{D}} \mathrm{f}$ for negative pictures was also greater than for neutral ones (Bonferroni correction, $p<0.001)$. For the delay group, a statistically significant effect for Valence was obtained, $F(159)=617.36, \mathrm{MSE}=4.48, \eta^{2}$ $=0.91, p<0.001$. The results were similar to those for the non-delay group. Thus, $B{ }^{\prime \prime} D$ for pleasant pictures was significantly higher than for unpleasant and neutral ones, and the value of $B{ }_{D}$ for negative pictures was also lower than for neutral pictures (Bonferroni correction, $p<$ 0.001). 


\section{Response Times}

The RT recorded during the recognition phase were subjected to a $2 \times 3$ ANOVA, considering the Status (old/new) and Valence (pleasant/ unpleasant/ neutral) of each picture. Table 1 shows the mean RT for both groups on the basis of valence and status of the pictures.

In the non-delay group, the ANOVA revealed statistically significant effects for the Status, $F(159)=15.07, \mathrm{MSE}=60684.10, \eta^{2}=0.20$, $p<0.001$, the Valence, $F(159)=39.51$, MSE $=120825.94, \eta^{2}=0.40, p<0.001$, and for the Status $\mathrm{x}$ Valence interaction, $F(159)=25.03$, MSE $=113752.60, \eta^{2}=0.30, p<0.001$. A more detailed analysis of this interaction was performed using the subsequent comparisons referring to the simple effects. It was found that for the old pictures, the RT were significantly higher for pleasant pictures than for unpleasant and neutral ones; moreover, RT was higher for unpleasant pictures than for neutral ones (Bonferroni correction for all comparisons, $p<$ 0.001). Nonetheless, none of these comparisons was statistically significant for the new pictures.

In the delay group, the principal effects of both Status, F (159) $=$ 28.79, MSE $=158716.81$, $\eta^{2}=0.33, \mathrm{p}<0.001$, and Valence, $\mathrm{F}(159)=$ 19.75, MSE $=46020.83, \eta^{2}=0.25, \mathrm{p}<0.001$, were statistically significant. Nonetheless, the Status $\mathrm{x}$ Valence interaction, F $(159)=2.95$, MSE $=27846.53, \eta^{2}=0.05$, was not significant, $\mathrm{p}=0.09$. The RT for pleasant pictures was significantly higher than for neutral ones (Bonferroni correction, $\mathrm{p}<0.001$ ); however, the RT was statistically similar between pleasant and unpleasant ones (Bonferroni correction, $\mathrm{p}=$ 0.099) and between the unpleasant and neutral pictures (Bonferroni correction, $\mathrm{p}=0.188$ ).

\section{Correlation Analyses}

Pearson's correlation analyses were also performed between the discrimination and bias parameters $\left(A^{\prime}\right.$, and $\left.B^{\prime \prime}\right)$, and the response times (see Table 1). The correlation between the response times and the accuracy measures $\left(A^{\prime}\right)$ was only significant for pleasant pictures in both groups of subjects, precisely the condition in which accuracy was greatest in each group. In general terms, an absence of correlation (values around 0 ) was observed between response times and $B_{D}$, in all comparisons. Lastly, a negative correlation was observed between the accuracy measurements $\left(A^{\prime}\right)$ and bias $\left(B^{\prime \prime}\right)$, which were statistically significant for the majority of conditions.

\section{Discussion}

The main aim of this paper was to study the modulating effects of emotional valence on the recognition memory for activating or high-arousal pictures. With this in mind, we used measures of accuracy or discrimination (parameter $A^{\prime}$ ) and response bias (parameter $\left.B_{D}{ }^{\prime}\right)$, as well as response times for recognition decisions, also performing bivariate correlations between these measures.

With regard to recognition accuracy, the most salient point is that the data obtained with the parameter $A^{\prime}$ evince a clear discrimination advantage for pleasant arousing pictures, in comparison with unpleasant and neutral ones, irrespective of the delay in the recognition test. These results are consistent with those of Fernández-Rey and Redondo (2007), who found greater discrimination for pleasant pictures in comparison with unpleasant ones, and with those of Atienza and Cantero (2008), who reported greater accuracy in recognition of pictures with an emotional content in comparison with neutral ones, particularly for those with high arousal and positive valence.

From an evolutionist perspective, emotions have adaptive functions, encouraging the preferential processing of emotional information relevant for survival. This is expressed through the preferential attention to the aforesaid information in the initial stages of registering the stimuli through to the later stages associated with memory processes. In this sense, those stimuli which elicit the greatest arousal, owing 
to their being linked to situations of survival for the individual, would entail higher priority in mnemic processing (Bradley et al., 1992; Kensinger, 2004). Such stimuli would serve to mobilise an approach motivation system and another of avoidance, so that both appetitive and aversive stimuli would receive preferential processing (Bradley, Moulder, \& Lang, 2005; Lang, Bradley, \& Cuthbert, 1990). On the other hand, even though the unpleasant and dangerous (e.g. threatening) stimuli are truly relevant for an individual in terms of survival, positive valence stimuli may be as or more relevant on the basis of the individual's goals (Lazarus, 1991; LeDoux, 1996). Our results relating to greater discrimination of pleasant pictures would seem to be consistent with this interpretation based on personal motivation and relevance. Those pictures of erotic content and related with adventure sports included in the pleasant pictures could be particularly relevant content for the group of young university students which made up the sample of participants. A similar interpretation has been used to explain the attention engagement capacity of pictures with different pleasant emotional contents (e.g., de Oca, Villa, Cervantes, \& Welbourne, 2012).

The best discrimination of pleasant arousing pictures occurred even when the recognition memory was tested immediately (non-delay group). This could support the interpretation that the best memory performance is a result of improved encoding of the emotional material in the initial acquisition stage (Christianson \& Loftus, 1991). Nonetheless, the improvement in recognition memory for pleasant pictures occurred to the same extent when the memory performance was tested after a delay (delay group) Thus, these results would seem to be more in favour of an explication of improved performance based on memory consolidation, in line with studies postulating important moderating effects of emotion in the memory consolidation process (e.g., McGaugh, 2004).

With regard to the response bias, the measurements obtained with parameter $B^{\prime \prime} D$ suggest a more conservative response bias for pleasant pictures in comparison with unpleasant and neutral ones, irrespective of the delay in recognition. These results are similar to those obtained in other studies (Fernández-Rey \& Redondo, 2007; Ochsner, 2000; Windman \& Kutas, 2001). Here it should be mentioned that the most conservative response bias was obtained for those pictures which were discriminated with the greatest accuracy, although negative correlations between accuracy and bias were obtained in the delay group for pictures of emotional content. The reasons behind these results are unclear, and will require further research.

Particularly noteworthy when examining recognition response times was the significant interaction between the status and valence variables when recognition occurred without delay. This suggests that the emotional content of pictures had a clear effect on immediate recognition memory. More specifically, the effects of valence only appeared in old pictures (hits) and not in new ones (correct rejections): recognition decisions were slower for pleasant pictures than for unpleasant and neutral ones. Also of interest was the high positive correlation between the response times and discrimination measurements, which only occurred for pleasant pictures. This result confirmed that the improved discrimination for these pictures was clearly associated to increased slowness in the recognition thereof, irrespective of the delay.

This increased slowness in recognition may well reflect the involvement of "recollection" processes, assuming that the slow responses imply a greater contribution from these processes, while rapid responses reflect "familiarity" (Yonelinas, 2002). The notion that the effects of valence on recognition memory do appear when there is "recollection" is supported by studies in which the states of consciousness which accompany the recognition of pictures of emotional content was evaluated by means of "remember-know" judgements. Thus, in the study by Atienza and Cantero (2008) greater accuracy in recognition based on "recollection" processes was reported for pictures with positive valence. Conversely, other studies (e.g. Humphreys, Underwood, \& Chapman, 2010; Ochsner, 2000) found that 
unpleasant pictures were more likely to be recollected than pleasant and neutral ones. On the other hand, exactly how memory strength alters RTs is unclear, as dissenting findings have suggested that "familiarity" can produce longer RTs, based on the notion that "remember" judgements may be more rapid than "know" judgments (Dewhurst, Holmes, Brandt, \& Dean, 2006; Wixted, 2009).

By way of conclusion, the methodology used in this work was sensitive to the detection of clear modulating effects of emotional valence on recognition memory for higharousal pictures. On the basis of rigorous experimental control of stimulus material, as well as convergent behavioural measures, a high level of homogeneity was obtained in the results with regard to the primacy or salience of the pleasant emotional content as opposed to the unpleasant or neutral content of the pictures. Participants demonstrated greater discrimination of pleasant pictures, increased slowness in the recognition thereof, and a more conservative attitude in their responses to the same. These results seem to suggest that improved discrimination of positive information with an adaptive function is possible. In these situations, the "recollection" processes for positive stimuli may be occurring with a view to executing approach behaviour towards them.

In any case, in order to reach more solid conclusions regarding the involvement of "recollection" and "familiarity" processes with regard to emotional valence, a comprehensive examination of the qualitative aspects of recognition memory will need to be conducted in future studies. To do so, it will be possible to use not only behavioural indices, such as "rememberknow" judgements, but also electrophysiological indices, such as the recording of evoked potentials. One well-known recognition memory ERP correlate is the "old-new" effect, according to which "old" items elicit more positive ERPs than "new" items. This effect is reflected in two components: one early, linked to processes based on "familiarity", and the other late, associated with "recollection" (for a review, see Rugg \& Allan, 2000). The use of both behavioural and electrophysiological indices would entail the availability of convergent measurements to detect the differential influence of emotional valence on the processes of "familiarity" and "recollection". This would help to clarify the inconsistency in results with regard to the effects of valence on recognition memory.

\section{References}

Atienza, M., \& Cantero, J. L. (2008). Modulatory effects of emotion and sleep on recollection and familiarity. Journal of Sleep Research, 17(3), 285-294. http://dx.doi.org/10.1111/j $.1365-2869.2008 .00661 . x$.

Bradley, M. M. (1994). Emotional memory: A dimensional análisis. In S. H. M. van Goozen, N. E. V. der Poll, \& J. A. Sergeant (Eds.), Emotions: Essays on emotion theory (pp. 97-134). Hillsdale, N. J.: Erlbaum.

Bradley, M. M., Greenwald, M. K., Petry, M. C., \& Lang, P. J. (1992). Remembering pictures: Pleasure and arousal in memory. Journal of Experimental Psychology: Learning, Memory and Cognition, 18(2), 379-390. Retrieved from https://www.ncbi.nlm.nih.gov/pubme $\mathrm{d} / 1532823$

Bradley, M. M, Moulder, B., \& Lang, P. J. (2005). When good things go bad: The reflex physiology of defense. Psychological Science, 16(6), 468-473. Retrieved from https://ww w.ncbi.nlm.nih.gov/pubmed/15943673

Christianson, S-A., \& Loftus, E. F. (1991). Remembering emotional events: The fate of detailed information. Cognition and Emotion, 5(2), 81-108. Retrieved from http s://philpapers.org/rec/CHRREE

Conroy, M. A., \& Polich, J. (2007). Affective valence and P300 when stimulus arousal levels controlled. Cognition and Emotion, 21 (4), 891-901. http://dx.doi.org/10.1080/ 02699930600926752

Conway, M. A. (1995). Flashbulb memories. Hillsdale, N.J.: Erlbaum.

de Oca B. M., Villa, M., Cervantes, M., \& Welbourne, T. (2012). Emotional modulation of the attentional blink by 
pleasant and unpleasant pictures. Journal of General Psychology, 139(4), 289-314.

Dewhurst, S. A., Holmes, S. J., Brandt, K. R., \& Dean, G. M. (2006). Measuring the speed of the conscious components of recognition memory: Remembering is faster than knowing. Consciousness $\mathbb{B}$ Cognition, 15(1), 147-162. Retrieved from https://ww w.ncbi.nlm.nih.gov/pubmed/16019226

Donaldson, W. (1992). Measuring recognition memory. Journal of Experimental Psychology: General, 121(3), 275-277.

Fernández-Rey, J., \& Redondo, J. (2007). Recognition memory for pictorial stimuli: Biasing effects of stimulus emotionality. Psicothema, 19(3), 375-380. Retrieved form http://www.psicothema.com/pdf/3373.pdf

Gordillo, F., Arana, J. M., Mestas, L., Salvador, J., Meilán, J. J. G., Carro, J., \& Pérez, E. (2010). Emoción y memoria de reconocimiento: la discriminación de la información negativa como un proceso adaptativo. Psicothema, 22(4), 765-771. Retrieved from http://www.unioviedo.es/re unido/index.php/PST/article/view/8950

Humphreys, L., Underwood, G., \& Chapman, P. (2010). Enhanced memory for emotional pictures: A product of increased attention to affective stimuli? European Journal of Cognitive Psychology, 22(8), 1225-1247. Retrieved from http://citeseerx.ist.psu.edu/viewdoc/d ownload?doi $=10 \cdot 1 \cdot 1 \cdot 406.8850 \&$ rep $=$ rep 1 $\&$ type $=$ pdf

Johansson, M., Mecklinger, A., \& Treese, A. C. (2004). Recognition memory for emotional and neutral faces: An eventrelated potential study. Journal of Cognitive Neuroscience, 16(10), 1840-1853. http://dx .oi.org/10.1162/0898929042947883

Kensinger, E. A. (2004) Remembering emotional experiences: The contribution of valence and arousal. Reviews in the Neurosciences, 15, 241-251. Retrieved from http://www2.bc.edu/elizabeth-kensing er/Kensinger RevNeurosci04.pdf

Lang, P. J. (1980). Behavioral treatment and bio-behavioral assessment: Computer applications. In J. B. Sidowski, J. H. Johnson, \& T. A. Williams (Eds.), Technology in mental health and delivery systems (pp. 119-137). Norwood, NJ: Ablex.

Lang, P. J., Bradley, M. M., \& Cuthbert, B. N. (1990). Emotion, attention and the startle reflex. Psychological Review, 97(3), 377-395. http://dx.doi.org/10.1037/0033-2 95X.97.3.377

Lang, P. J., Bradley, M. M., \& Cuthbert, B. N. (1999). International affective picture system (IAPS): Technical manual and affective ratings. Gainesville, FL: The Center for Research in Psychophysiology, University of Florida.

Lazarus, R. S. (1991). Emotion and adaptation. New York: Oxford University Press.

LeDoux, J. E. (1996). The emotional brain: The mysterious underpinnings of emotional life. New York, NY, US: Simon \& Schuster.

McGaugh, J. L. (2004). The amygdala modulates the consolidation of memories of emotionally arousing experiences. Annual Review of Neuroscience, 27, 1-28. http://dx.doi.org/10.1146/annurev.ne uro.27.070203.144157

Moltó, J., Montañés, S., Poy, R., Segarra, P., Pastor, M. C., Tormo, M. P., ... Vila, J. (1999). Un nuevo método para el estudio experimental de las emociones: el International Affective Picture System (IAPS). Adaptación española. Revista de Psicología General y Aplicada, 52 (1), 55-87.

Ochsner, K. N. (2000). Are affective events richly recollected or simply familiar? The experience and process of recognizing feelings past. Journal of Experimental Psychology: General, 129(2), 242-261. Retrieved from https://www.ncbi.nlm.nih.g ov/pubmed/10868336

Redondo, J., \& Fernández-Rey, J. (2010). Reconocimiento de fotografías de contenido emocional: Efectos de la valencia cuando se controla el arousal. Psicológica, 31(1), 65-86. Retrieved from http://www.uv.es/revispsi/articulos1.1 0/4REDONDO.pdf 
Reisberg, D., \& Heuer, F. (2004). Remembering emotional events. In D. Reisberg \& $\mathrm{P}$. Hertel (Eds.). Memory and emotion (pp. 3-41). Nueva York: Oxford University Press.

Rugg, M. D., \& Allan, K. (2000). Event-related potential studies of memory. In E. Tulving \& F. I. M. Craig (Eds.), The Oxford handbook of memory (pp. 521-537). Oxford, UK: Oxford University Press.

Schulkind, M. D., \& Woldorf, G. M. (2005). Emotional organization of autobiographical memory. Memory $\& 3$ Cognition, 33(6), 1025-1035. http://dx.doi.org/10.3758/BF03 193210

Snodgrass, J. G., Levy-Berger, G., \& Haydon, M. (1985). Human experimental psychology (pp. 549-554). New York: Oxford University Press.

Windmann, S., \& Kutas, M. (2001). Electrophysiological correlates of emotioninduced recognition bias. Journal of Cognitive Neuroscience, 13(5), 577-592. http://dx.doi.org/10.1162/089892 901750363172

Wixted, J. (2009). Remember/know judgments in cognitive neuroscience: An illustration of the underrepresented point of view. Learning and Memory, 16, 406-412. http://d x.doi.org/10.1101//m.1312809

Yonelinas, A. P. (2002). The nature of recollection and familiarity: A review of 30 years of research. Journal of Memory and Language, 46(3), 441-517. http://dx.doi.org /10.1006/jmla.2002.2864

\section{Notes}

* Research article.

[1] The IAPS picture numbers were as follows: Old pleasant: 4607, 4659, 4690, 5626, 5628, 8030, $8080,8250,8300,8400$. Old unpleasant: 2053, 2100, 5940, 6300, 6312, 6900, 6940, 9140, 9340, 9600. Old neutral: $1274,1640,2210,2410,5900,5950$, $7130,7500,8010,9090$. New pleasant: 8220,8090 , $8260,8040,8180,8034,8031,4680,5623,8161$, 8370, 8210, 4664, 5629, 8170, 4608, 4653, 5621, 8490,8420 . New unpleasant: 6831, 9007, 9560, 9570,
$9430,3300,6020,9404,8230,6530,9620,6350$, $9800,9520,6200,9230,9622,2130,7380,1930$. New neutral: 9390, 7560, 1302, 1390, 1931, 9270, 2661, $9182,6150,7050,2220,7510,9210,7710,2600$, $1660,1560,1650,8050,5990$.

[2] Following these authors, the following formulae were used for the calculation of $A^{\prime}$ and $B^{\prime \prime} D(H=$ hits ; FA $=$ false alarms):

$$
\begin{aligned}
& A^{\prime}=0.5+[(\mathrm{H}-\mathrm{FA})(1+\mathrm{H}-\mathrm{FA})] /[4 \mathrm{H}(1-\mathrm{FA})], \text { if } \mathrm{H}>\mathrm{FA} \\
& A^{\prime}=0.5, \text { if } \mathrm{H}=\mathrm{FA} \\
& A^{\prime}=0.5-[(\mathrm{FA}-\mathrm{H})(1+\mathrm{FA}-\mathrm{H})] /[4 \mathrm{FA}(1-\mathrm{H})], \text { if } \mathrm{H}<\mathrm{FA} \\
& B^{\prime \prime}{ }_{D}=[(1-\mathrm{H})(1-\mathrm{FA})-\mathrm{HxFA}] /[(1-\mathrm{H})(1-\mathrm{FA})+\mathrm{HxFA}]
\end{aligned}
$$

